\title{
Nodular regenerative hyperplasia of the liver with membranous glomerulonephritis
}

\author{
A. J. McCulloch* \\ B.Sc., M.R.C.P. \\ A. R. MORLEY* \\ M.B., M.R.C.Path. \\ R. WILKINSON* \\ M. LESNA $\dagger$ \\ M.D., F.R.C.P. \\ M.D., M.R.C.Path. \\ *Freeman Hospital, and $\uparrow$ Newcastle General Hospital, Newcastle upon Tyne
}

\begin{abstract}
Summary
Nodular regenerative hyperplasia of the liver is an uncommon disorder, the main consequence of which is portal hypertension, hepatocellular decompensation being uncommon. A case associated with membranous glomerulonephritis is reported, in which death was caused by fulminant hepatic failure.

Introduction

Membranous glomerulonephritis occurs in association with neoplasms of several organs (Lee Yamaucki and Hopper, 1966) and also with nonmalignant hepatic lesions including $\mathrm{HB}_{\mathrm{s}}$ and $\mathrm{HB}_{\mathrm{e}}$ antigenaemia (Takekoshi et al., 1979), primary biliary cirrhosis (Rai et al., 1977), alcoholic cirrhosis (Callard et al., 1975) and chronic active hepatitis (Cogan, Graber and Connor, 1977). The nephritis is thought to be a consequence of circulating immune complex deposition in the kidney. The association of nodular regenerative hyperplasia has not, so far as can be ascertained, previously been reported.
\end{abstract}

\section{Case report}

The patient developed nephrotic syndrome at the age of $\mathbf{4 5}$ years and renal biopsy at that time showed membranous glomerulonephritis. During follow-up plasma creatinine was stable at $150 \mu \mathrm{mol} / \mathrm{l}$ and urinary protein did not exceed $5 \mathrm{~g} / 24 \mathrm{hr}$, but he developed discharging skin lesions which improved with erythromycin and histologically showed no evidence of vasculitis. After 2 years he presented as an emergency, semi-comatose, with a 2-week history of nausea and vomiting. On examination he was mildly dehydrated but there was no pyrexia, lymphadenopathy or jaundice. Fluctuant discharging skin lesions were noted, particularly over his knees and elbows and there were perianal ulcers. There was a little ascites but no clinically detectable hepatic or splenic enlargement and no oedema. There were no abnormal neurological signs. Investigations showed $\stackrel{\circ}{+}$ (normal values in brackets): $\mathrm{Hb} 20.4 \mathrm{~g} / \mathrm{dl}$, MCV N $100 \mathrm{fl}$, HCT $0.524 \mathrm{l} / \mathrm{l}$, ESR $5 \mathrm{~mm} / \mathrm{hr}$. Blood film 옥 showed target cells and bone marrow examination was normal. Creatinine $196 \mu \mathrm{mol} / \mathrm{l}(53-124)$; urea $7.4 \mathrm{mmol} / 1$ (2.5-7.0); glucose $3.6 \mathrm{mmol} / 1$; calcium $\overparen{\mathrm{D}}$ $1.88 \mathrm{mmol} / \mathrm{l}(2.25-2.75)$. Phosphate $1.21 \mathrm{mmol} / \mathrm{b} \vec{\bullet}$ $(0 \cdot 6-1 \cdot 30)$; alkaline phosphatase (liver origin) $339 \stackrel{\infty}{-}$ i.u./l (28-92); aspartate amino transferase 57 i.u. (2-21); albumin $16 \mathrm{~g} / 1$ (34-50); total protein $54 \mathrm{~g} /$ (60-80). Bilirubin $14 \mu \mathrm{mol} / 1$ (17); prothrombin time $13 \mathrm{sec}$ (control 13). Immunoglobulins: IgG $15 \cdot 25 \mathrm{~g} / 1$ (9.5-16.5), IgM $1.55 \quad(0.65-2.00), \quad$ IgA $6.90 \mathrm{~g} / 1 \stackrel{\circ}{\circ}$ $(0 \cdot 90-4 \cdot 50)$. $\mathrm{HB}_{\mathrm{s}} \mathrm{Ag}$ was negative. Alphafoetopro- $\propto$ tein was $59 \mathrm{MRC}$ units/ml (up to 6 may be insignifi- $\overrightarrow{\overrightarrow{0}}$ cant). $\mathrm{C}_{3} \quad 0.84 \mathrm{~g} / 1 \quad(0 \cdot 8-1 \cdot 4) . \mathrm{C}_{4} \quad 0.38 \mathrm{~g} / 1 \quad(0 \cdot 1-0 \cdot 4)$. Urinary protein excretion was $1.6 \mathrm{~g} / 24 \mathrm{hr}$. Blood, urine and sputum cultures were sterile as were skin swabs. Chest X-ray was normal. IVP showed poor concentration of contrast but was otherwise normal. Barium swallow showed small varices. Barium meal and follow-through was normal. Liver scan showed small liver with little uptake of colloid. The spleen was enlarged. Percutaneous and later perlaparoscopic liver biopsies showed irregular proliferation of hepatocytes with scanty fibrous septae and the laparoscopy had shown several umbilicated lesions on the liver surface.

He subsequently developed rapidly deteriorating renal function, deepening jaundice, hyponatraemia, hypoglycaemia, gastrointestinal bleeding and he died 6 weeks after admission to hospital.

Post-mortem examination showed haematomas in muscle, subcutaneous tissue and lung. Chronic pancreatitis was noted and the liver appeared macroscopically involved in diffuse hepatocellular carcinoma. The histological appearance of the liver, however, was of nodular regenerative hyperplasia with superadded acute focal damage to hepatocytes 


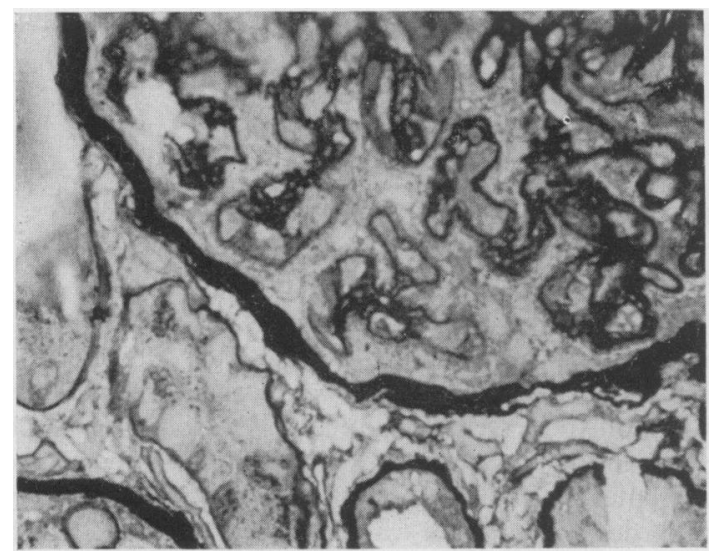

FIG. 1. Renal biopsy. On the epithelial surface of the basement membranes are numerous spikes, characteristic of membranous glomerulonephritis (PASM stain, $\times 800$ ).

but no true hepatitis. Immunoperoxidase staining for alphafoetoprotein was negative but carcinomembryonic antigen was detected in the needle biopsy liver sample.

\section{Discussion}

Nodular regenerative hyperplasia (NRH) is an uncommon hepatic lesion of which portal hypertension is the main consequence. Manifestations of severe liver failure are usually absent but associated features include rheumatoid arthritis; the calcinosis cutis-Raynaud's phenomenon-sclerodactyly-telangiectasia (CRST) syndrome; bacterial endocarditis; and monoclonal gammopathy (Rougier et al., 1978). Although there was no direct evidence of active immune complex disease in the present patient, it is postulated that, in view of the above 'immune' associations of $\mathrm{NRH}$, his membranous glomerulonephritis was associated with NRH by more than chance.

\section{References}

Callard, P., Feldmann, G., Prandi, D., Belair, M., Mandet, C., Weiss, Y., Duret, P., Banhaman, J.P. \& BARRIETY, J. (1975) Immune complex type glomerulonephritis in sclerosis of the liver. American Journal of Pathology, 80, 329.

Cogan, M., Graber, M. \& Connor, D. (1977) Chronic active hepatitis and membranous glomerulonephritis. American Journal of Gastroenterology, 68, 386.

LEE, J.C., YAMAUCKI, H. \& HOPPER, J. (1966) The association of cancer and the nephrotic syndrome. Annals of Internal Medicine, 64, 41.

RaI, G.S., Hamlyn, A.N., Dahl, M.G., Morley, A.R. \& WiLkinson, R. (1977) Primary biliary cirrhosis, cutaneous capillaritis and IgM-associated membranous glomerulonephritis. British Medical Journal, 1, 817.

Rougier, P., Degott, C., Rueff, M.D. \& Benhamon, J.P. (1978) Nodular regenerative hyperplasia of the liver. Gastroenterology, 75, 169.

Takekoshi, Y., TanaKa, M., MiYakawa, Y., Yoshizawa, H., TAKAHASHI, K. \& MaYUmi, M. (1979) Free 'small' and IgG-associated 'large' hepatitis B e antigen in the serum and glomerular capillary walls of two patients with membranous glomerulonephritis. New England Journal of Medicine, 300, 814. 